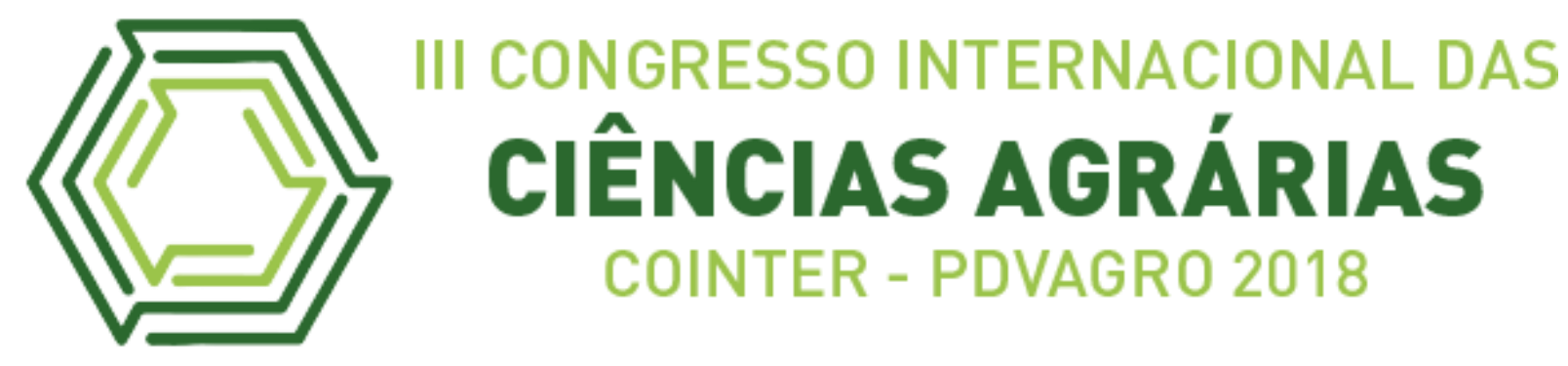

\title{
CULTIVO DE ALFACE (Lactuca sativa L.) SOB DIFERENTES COMPOSIÇÕES DE NPK
}

\section{LETTUCE CULTIVATION (Lactuca sativa L.) UNDER DIFFERENT NPK COMPOSITIONS}

\begin{abstract}
Apresentação: Pôster
Altevir Fonseca de Oliveira Neto ${ }^{1}$; Amanda Catarine Ribeiro da Silva ${ }^{2}$, Janete Silva do Nascimento $^{3}$, Júlia Karoline Rodrigues das Mercês ${ }^{4}$, Davi Henrique Lima Teixeira ${ }^{5}$.
\end{abstract}

\section{DOI: https://doi.org/10.31692/2526-7701.IIICOINTERPDVAGRO.2018.00410}

\section{Introdução}

A Alface (Lactuca sativa L.) encontra-se na família Asteraceae e é uma hortense muito usada na alimentação humana em todo o mundo por conter altos teores vitamínicos que beneficiam a população. A hortaliça tem grande valor comercial no Brasil e se destaca por ser a sexta em importância econômica e oitava em produção (OLIVEIRA, 2005). Segundo Oliveira (2004), o grande valor desta folhosa se deve ao sabor, qualidade nutritiva e principalmente a facilidade de aquisição e baixo custo no comércio.

A aplicação de fertilizantes para aumentar a produtividade da alface é muito comum nos sistemas de plantio, quando esses fertilizantes são aplicados de forma correta e equilibrada pode-se atingir resultados satisfatórios ao longo da produção. Rodrigues e Casali (1999) verificou que a adubação aumenta os teores de nutrientes nas plantas. Comumente a diversos vegetais, a alface apresenta baixos teores de fixação quando se trata do macronutriente $\mathrm{P}$, já em relação ao $\mathrm{N}$ e K os teores acumulados são mais altos (GRANGEIRO et al., 2006). Objetivou-se analisar os efeitos causados por diferentes composições de adubações NPK na cultura da alface, variedade Mônica, no município de Capitão Poço.

\section{Fundamentação Teórica}

Na obtenção de uma produção eficaz, é necessário levar-se em consideração diversos

\footnotetext{
${ }^{1}$ Agronomia, Universidade Federal Rural da Amazônia, an123deoliveira4@ hotmail.com;

2 Agronomia; Universidade Federal Rural da Amazônia, amandakrds@ hotmail.com;

${ }^{3}$ Agronomia, Universidade Federal Rural da Amazônia, janetenascimento_@outlook.com;

${ }^{4}$ Agronomia, Universidade Federal Rural da Amazônia, juliakaroline.j@ hotmail.com;

${ }^{5}$ Doutor; Universidade Federal Rural da Amazônia, davi.teixeira@ufra.edu.br.
} 
fatores como clima, temperatura, umidade, solo, entre outros. O ideal é que o cultivo seja feito em solos de textura média, rico em matéria orgânica com altos teores nutricionais, bem drenados e com boa aeração. As maiores produções podem ser obtidas a partir da melhoria das características químicas e físico-química do solo, o que pode ser obtida com o acréscimo de doses crescentes de nutrientes (Souza et al., 2005).

A aplicação de fertilizantes minerais auxilia na reposição de nutrientes que as plantas necessitam, entretanto, este processo deve ser feito de forma regulada para que a cultura não seja prejudicada, a alface caracteriza-se por ser sensível, desta forma, sua adubação deve ser equilibrada. Os nutrientes mais exigidos, N, P, K, auxiliam em diversos processos metabólicos da planta. O nitrogênio auxilia em processos como fotossíntese e multiplicação e regeneração celular, além de, quando disponibilizado para a planta influi em crescimento de peso seco variando de 2 a 5\%. Essas taxas variam de acordo com a espécie, estagio de desenvolvimento (Silva Júnior \& Soprano, 1997). O potássio é um nutriente necessário na divisão celular e na abertura e fechamento dos estômatos. (Malavolta, 1996). Tratando-se de fósforo, este nutriente é pouco disponível para as plantas em solos tropicais, a cultura da alface responde bem quando este nutriente está disponível para absorção. Comparando com os outros macronutrientes, os teores de P absorvidos, são baixos (Grangeiro et al., 2006; Kano; Cardoso; Villas Bôas, 2011).

\section{Metodologia}

O trabalho foi realizado na área experimental da Universidade Federal Rural da Amazônia (UFRA), campus Capitão Poço, em casa de vegetação no período de março a maio de 2016. As sementes alface utilizadas foram compradas em casa agropecuária e pertencem à marca FELTRIN, Cultivar Mônica e germinação de 91\%. As sementes de alface foram primeiramente cultivadas em copos de plástico de $150 \mathrm{ml}$ preenchidos com terra preta, contendo cinco sementes por copo. 25 DAS, as plântulas foram transplantadas para sacos plásticos de dimensão $30 \mathrm{~cm}$ x $15 \mathrm{~cm}$, onde também iniciou adubação que compõem os tratamentos.

Utilizou-se delineamento experimental inteiramente casualizado no qual as mudas de alface foram submetidas a oito tratamentos: $0, \mathrm{~N}, \mathrm{P}, \mathrm{K}, \mathrm{NP}, \mathrm{NK}, \mathrm{PK}, \mathrm{NPK}$ e quatro repetições, totalizando 32 unidades experimentais, sendo que cada unidade experimental foi composta por uma planta/vaso. As doses testadas nos tratamentos foram $\mathrm{N}=0,49 \mathrm{~g} / \mathrm{planta}$, 
$\mathrm{P}=7,5 \mathrm{~g} /$ planta, $\mathrm{K}=1,49 \mathrm{~g} /$ planta conforme recomendada no Manual de Adubação do Estado do Pará (CRAVO et al., 2010).

As análises avaliadas foram Massa Fresca da Parte Aérea (MSFA) e Massa Fresca da Raiz (MFR) e Área Foliar (AF). Os dados foram testados quanto aos pressupostos de normalidade através do teste de Shapiro-Wilk e demostraram homogeneidade, posteriormente foi submetida à análise de variância, sendo as médias comparadas pelo teste de Tukey ao nível de $1 \%$ de probabilidade, com o uso do software estatístico AGROESTAT (BARBOSA e MALDONARO, 2014).

\section{Resultados e Discussões}

Os resultados das variáveis analisadas Massa Fresca da Parte Aérea (MFPA), Massa Fresca da Raiz (MFR) e Área foliar (AF) demonstraram respostas significativas, pelo teste $\mathrm{F}$ $(\mathrm{P}<0,01)$, para o macronutriente fósforo e AF apresentou diferença significativa para os nutrientes fósforo e potássio (TABELA 1).

As plantas que receberam somente o $\mathrm{P}$ como tratamento obtiveram maiores valores nas variáveis avaliadas (MFPA, MFR e AF). Isso acontece porque na nutrição mineral de plantas, o fósforo tem função de destaque no metabolismo da planta, principalmente no controle da atividade enzimática (FAQUIN, 1994). Além disso, esse nutriente apresenta função estrutural e está ligado a processos metabólicos importantes tais como, transferência e armazenamento de energia. Plantas sob deficiência de $\mathrm{P}$ podem apresentar processos como redução da altura, redução da matéria seca, redução da área foliar e na produção conforme foi relatado por Almeida et al. (2011).

TABELA 1. Análise estatística em relação das variáveis MFPA, MFR e AF da cultura da alface cv. Mônica. UFRA. Capitão Poço/PA. Fonte: Prórpia.

\begin{tabular}{ccccc}
\hline $\begin{array}{c}\text { Causa de } \\
\text { Variação }\end{array}$ & G.L & QM/MFPA & QM/MFR & QM/AF \\
\hline Efeito Fator N & 1 & $0,0050 \mathrm{NS}$ & $0,0288 \mathrm{NS}$ & $0,0001 \mathrm{NS}$ \\
Efeito Fator P & 1 & $0,0882^{* *}$ & $2,0706^{* *}$ & $0,0913^{* *}$ \\
Efeito Fator K & 1 & $0,0012 \mathrm{NS}$ & $0,0648 \mathrm{NS}$ & $0,0026 \mathrm{NS}$ \\
Ef. Int. NxP & 1 & $0,0036 \mathrm{NS}$ & $0,1404 \mathrm{NS}$ & $0,0019 \mathrm{NS}$ \\
Ef. Int. NxK & 1 & $0,0001 \mathrm{NS}$ & $0,0528 \mathrm{NS}$ & $0,0013 \mathrm{NS}$ \\
Ef. Int. PxK & 1 & $0,0045 \mathrm{NS}$ & $0,0544 \mathrm{NS}$ & $0,0108^{*}$ \\
Ef. Int. NxPxK & 1 & $0,0000 \mathrm{NS}$ & $0,4095 \mathrm{NS}$ & $0,0022 \mathrm{NS}$ \\
\hline Tratamentos & 7 & - & - & - \\
Resíduo & 24 & 0,0020 & 0,0739 & 0,0014 \\
Total & 31 & - & - & - \\
\hline
\end{tabular}


Coeficiente de

Variação

$(* *)$ significativo $1 \% ;(*)$ significativo $5 \%$; (NS) não significativo.

Resultados semelhantes foram obtidos por Lana et al. (2004) e por Kano, Cardoso e Villas Bôas (2011), que também detectaram aumento acentuado no crescimento de plantas de alface quando receberam a adubação fosfatada.

Foi possível verificar que houve interação entre fósforo e potássio para a variável Área Foliar. As interações que ocorrem entre os nutrientes podem ser favoráveis (sinérgica), quando um nutriente contribui na absorção de outro, ou desfavoráveis (antagônica), onde um nutriente pode prejudicar a absorção de outro (TABELA 2). Prado (2008), afirma que embora o processo de absorção de nutrientes seja específica e seletiva, algumas vezes ocorre competição entre eles, pelo que ambos nutrientes provavelmente compartilham o mesmo transportador (carregador).

TABELA 2. Desdobramento e média do desdobramento da interação fósforo e potássio referente à variável $\mathrm{AF}$ da cultura da alface cv. Mônica. UFRA. Capitão Poço/PA. Fonte: Prórpia.

\begin{tabular}{ccc}
\hline AF & \multicolumn{2}{c}{ Média do desdobramento } \\
\hline & $\mathrm{P} 0$ & $\mathrm{P} 1$ \\
\hline $\mathrm{K} 0$ & $1,25 \mathrm{bA}$ & $1,39 \mathrm{aA}$ \\
$\mathrm{K} 1$ & $1,27 \mathrm{bA}$ & $1,34 \mathrm{aB}$ \\
\hline
\end{tabular}

Em relação à média da variável área foliar, observou-se que as plantas testemunhas, ou seja, as que não receberam adubação, as médias tendiam a diminuir. Conforme Fonseca (2013) uma nutrição da cultura da alface pode assegurar uma produção de qualidade, alem de ser de extrema importância, sendo assim, o manejo da adubação deve ser conhecido e planejado para esse fim.

Ao verificar o tratamento que recebeu somente adubação fosfatada, observa-se que o mesmo obteve a maior média quando comparados com os outros. Isso acontece porque a alface é considerada como uma cultura bastante exigente em fósforo, principalmente na fase final de seu ciclo, já que este macronutriente participa de vários compostos e reações metabólicas (MARSCHNER,1995).

No entanto, quando adicionado fósforo e potássio juntos como único tratamento, houve a diminuição da média da variável resposta (AF). Silva (2015) afirma que os transportadores iônicos raramente são específicos e os íons podem competir diretamente pelo transporte. Além disso, essa competição é influenciada pelas propriedades do próprio 
transporte e pela diferença na concentração dos íons na solução do solo. Portanto para se obter boas produções na cultura da alface é necessário compreender as interações dos nutrientes entre si e com o solo, para que se possa manejá-las de maneira correta.

\section{Conclusões}

A adubação fosfatada influenciou de maneira positiva nas variáveis Massa Fresca da Parte Aérea, Massa fresca da Raiz e Área Foliar, fazendo com que as plantas obtivessem maiores valores nas variáveis respostas, os outros tratamentos não apresentaram respostas significativas. O melhor tratamento encontrado para as condições do experimento e que obteve maior média para Área Foliar foi o que continha o P e não continha o K, visto que o segundo agia de maneira antagônica a absorção do primeiro.

\section{Referências}

ALMEIDA, T. B. F. de; PRADO, R. M.; CORREIA, M. A. R.; PUGA, A. P.; BARBOSA, J. C. Avaliação nutricional de alface cultivada em soluções nutritivas suprimidas de macronutrientes. Revista Biotemas, vol. 24, n. 02, jul., 2011.

CRAVO, M. S.; VIEGAS, I. J. M.; BRASIL, E. C. Recomendações de Adubação e Calagem para o Estado do Pará. Embrapa Amazônia Oriental, Belém,1ºd. p. 262. 2010.

FAQUIM, V. Nutrição mineral de plantas. Lavras: FAEPE. p. 227. 1994.

FONSECA, A. S. et al. Análise de Crescimento e Absorção de Fósforo em Alface. Nucleus, V. 10, n. 2, p. 234, 2013.

GRANGEIRO, L. C. et al. Acúmulo de nutrientes por três cultivares de alface cultivados em condições do Semi-Árido. Horticultura Brasileira, Brasília, V. 24, n.2, p. 190-194, 2006

SILVA, M. L. S.; TREVIZAM, A. R. INTERAÇÕES IÔNICAS E SEUS EFEITOS NA NUTRIÇÃO DAS plANTAS.Informções Agronomicas No 149 - Março/ 2015

KANO, C.; CARDOSO, A. I. I.; VILLAS BÔAS, R. L. Acúmulo de nutrientes pela alface destinada à produção de sementes. Horticultura Brasileira, Brasília, v. 29, n. 1, p. 70-77, 2011.

LANA, R. M. Q.; ZANÃO JUNIOR, L. A.; LUZ, J. M. Q.; SILVA, J. C. Produção de alface em função do uso de diferentes fontes de fósforo em solo de Cerrado. Horticultura Brasileira, Brasília, v. 22, n. 3, p. 525-528, 2004.

MALAVOLTA, E. Potássio é uma grande realidade - o potássio é essencial para todas as plantas. Informações Agronômicas, Piracicaba, n. 73, p. 5-6, mar. 1996.

MARSCHNER, H. Mineral Nutrition of higher plants. London: Academic Press, 1995. 889p. 
MULLER, A.G. Comportamento térmico do solo e do ar em alface em diferentes tipos de cobertura do solo. 1991. 77f. Dissertação (mestrado) -Escola Superior de Agricultura "Luiz de Queiroz”, Universidade de São Paulo, Piracicaba, 1991.

Oliveira, A. C. B.; Sediyama, M. A. N.; Pedrosa, M. W.; Garcia, N. C. P.; Garcia, S. L. R. Divergência genética e descarte de variáveis em alface cultivada sob sistema hidropônico. Acta Scientiarum Agronomy, v.26, p.211-217, 2004.

OLIVEIRA, A. M. C. Avaliação da qualidade higiênica de alface minimamente processada, comercializada em Fortaleza, CE. Higiene Alimentar, v.19, n.135, p.80-85, 2005.

PRADO, R. de M. Nutrição de plantas. editora UNESP, 2008.

RODRIGUES, E. T.; CASALI, V. W. Rendimento e concentração de nutrientes em alface, em função das adubações orgânica e mineral. Horticultura Brasileira, v. 17, n. 2, p. 125-128, 1999.

SILVA JÚNIOR, A. A.; SOPRANO, E. Caracterização de sintomas visuais de deficiências nutricionais em alface. Florianópolis: EPAGRI, 1997. 57 p.

SOUZA, P.A.; NEGREIROS, M.Z.; MENEZES, J.B.; BEZERRA NETO, F.; SOUZA, G.L.F.M.; CARNEIRO, C.R; QUEIROGA, R.C.F. Características químicas de alface cultivada sob efeito residual da adubação com composto orgânico. Horticultura Brasileira, Brasília, v. 23, n.3, p. 754-757, jul set.2005. 